Article

\title{
Dynamic Analysis of an Underwater Cable-Driven Manipulator with a Fluid-Power Buoyancy Regulation System
}

\author{
Tong Wang ${ }^{1}$, Zihao You ${ }^{1}$, Wei Song ${ }^{1,2,3,4, *(1)}$ and Shiqiang Zhu ${ }^{1,2}$ \\ 1 Ocean College, Zhejiang University, Zhoushan 316021, China; 3160100561@zju.edu.cn (T.W.); \\ youzh8@163.com (Z.Y.); sqzhu@sfp.zju.edu.cn (S.Z.) \\ 2 Zhejiang Lab, Hangzhou 311100, China \\ 3 Institute of Robotics, Zhejiang University, Yuyao 315400, China \\ 4 The Engineering Research Center of Oceanic Sensing Technology and Equipment, Ministry of Education, \\ Zhoushan 316021, China \\ * Correspondence: weisong@zju.edu.cn; Tel.: +86-138-6721-8612
}

Received: 8 November 2020; Accepted: 25 November 2020; Published: 26 November 2020

check for updates

\begin{abstract}
This article presents an underwater cable-driven manipulator (UCDM) with a buoyancy regulation system (BRS), which is controlled by a fluid-power system. The manipulator consists of five sections, and each section is embedded with a buoyancy adjustment unit. By regulating buoyancy at each section, the static and dynamic states of the manipulator will be changed, promising a new operating mode of an underwater manipulator driven by buoyancy. In this article, a dynamic model of the manipulator is established by the Newton-Euler equation, considering cable tension, inter-joint force, buoyancy, water resistance and other variables. With a numerical method, the dynamic model is solved and the values of cable tension are obtained, which are used to evaluate the buoyancy-driven operating mode of underwater manipulator. This research will be useful for manipulator operating in fluid environments, such as underwater manipulator in the ocean, micro-manipulator in a blood vessel, and so on.
\end{abstract}

Keywords: underwater manipulator; cable-driven manipulator; buoyancy regulation; dynamic modeling

\section{Introduction}

Underwater manipulators are widely applied in the exploitation of ocean resources, which can assist people in multiple tasks such as collecting marine samples [1], gripping underwater objects [2], operating and maintaining underwater equipment of oil and gas [3]. They are now indispensable engineering equipment for marine development [4-8].

Traditional underwater manipulators mainly adopt a rigid structure with a large body mass and moment of inertia. Therefore, they are not suitable for operations in narrow and complicated environments such as underwater pipelines and sunken ships $[9,10]$. In comparison, the cable-driven manipulator is widely used in fields like nuclear power [11,12], medical $[13,14]$ and aviation $[15,16]$, which are above the water, due to its high degree of freedom (DOF) and large workspace $[13,14,17-20]$. If the cable-driven manipulator can be applied in underwater scenes, it will have a significant potential in marine exploration and resource development $[2,10]$, which is also meaningful for the development of manipulators operating in fluid environments like micro-manipulators used in medical fields [21-24].

Increasing the number of joints and the length of the arm can increase the flexibility of the cable-driven manipulator and expand its range of operation. However, this also increases the 
self-weight of the manipulator, resulting in additional power consumption of motors to balance the impact of the self-weight. At present, researchers have carried out some research on this issue. Thrusters, such as water jets [25] and propellers [26], are installed on the manipulator to compensate the manipulator's self-weight. In addition, Masashi Takeichi's team developed the Giacometti series of manipulators, which balance the weight of the manipulator through buoyancy generated by helium gas [27]. Since the buoyancy-driven scheme neither needs to consume energy continuously, nor to install thrusters on the manipulator, the scheme proposed by reference [27] has more advantages than that of references $[25,26]$. Therefore, we design a fluid-power buoyancy regulation system for an underwater cable-driven manipulator (UCDM). It is expected that the buoyancy regulation system (BRS) could weaken the influence of the UCDM's self-weight, thereby helping to improve the operating performance of the UCDM.

In recent years, researches on cable-driven manipulators are mainly aimed at on-land operations, focusing on the motion control [28-30], kinematic [31,32] and dynamic [33,34] modeling. These studies rarely involve underwater applications [10], and have not yet combined buoyancy driving with UCDM. For the underwater operation environment, hydrodynamic factors such as buoyancy and water resistance make the dynamic model of the UCDM more complicated. Guohua Xu et al. studied the influence of hydrodynamic factors on the dynamics of an underwater manipulator [35]. They found that the buoyancy has the greatest impact on underwater manipulators, which is the same order of magnitude as the gravity of the manipulator. Therefore, for the buoyancy-driven scheme, it is of great significance to establish the dynamic model of the UCDM and to explore the effect of buoyancy on the manipulator [36,37].

In the dynamic model, the cable tension directly influents the motion state of the UCDM, and reflects BRS's effect on the UCDM. Therefore, our research focuses on BRS's effect on the cable tension during the action of the UCDM in underwater operations.

In this article, an underwater cable-driven manipulator with a fluid-power buoyancy regulation system is firstly proposed. The UCDM is composed of five arm sections with embedded BRS, which can compensate gravity by regulating buoyancy in each section. Secondly, based on the mechanical structure and working principle of the UCDM, a dynamic model is established using Newton-Euler method, including cable tension, inter-joint force, buoyancy, water resistance and other variables. We solve the dynamic model through numerical calculation and obtain the time-varying value of each variable. Then we analyze BRS's effect on the cable tension of the UCDM. Finally, a conclusion is drawn providing a theoretical basis for a future buoyancy-driven scheme.

\section{Mechanical Structure and Working Principle}

\subsection{Overall Structure of the Manipulator}

The overall mechanical structure of the UCDM proposed in this article is shown in Figure 1. It consists of a driving system and a cable-driven manipulator. The driving system includes cables and motors mounted on the base. The manipulator is composed of five arm sections with embedded BRS. Adjacent sections are coupled by cross universal joints. According to task requirements, the manipulator can expand the number of sections to improve its adaptability in operations. Considering the need of self-weight reduction and rust prevention, 6061 aluminum alloy is selected as the main material of the UCDM. The specifications of the manipulator are shown in Table 1. 


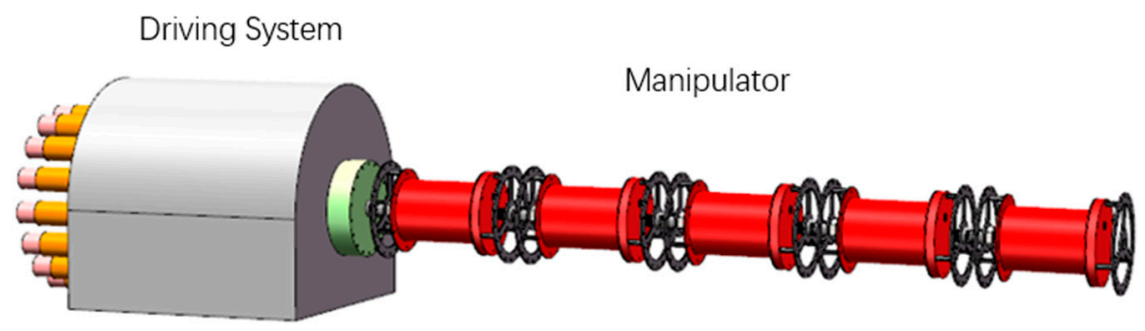

Figure 1. Mechanical structure of the manipulator.

Table 1. The specifications of the manipulator.

\begin{tabular}{cc}
\hline Characteristics & Value \\
\hline Size $(\mathrm{L} \times \mathrm{W} \times \mathrm{H})$ & $1012 \mathrm{~mm} \times 116 \mathrm{~mm} \times 116 \mathrm{~mm}$ \\
\hline Weight $($ moving parts) & $2.55 \mathrm{~kg}$ \\
\hline Maximum payload & $4.5 \mathrm{~kg}$ \\
\hline Load-to-weight ratio $^{1}$ & 1.76 \\
\hline Joint rotation range & $\pm 30^{\circ}$ \\
\hline The load-to-weight ratio is the ratio of payload to the weight of moving parts
\end{tabular}

\subsection{Structure of a Section}

As shown in Figure 2, an arm section consists of two wiring disks, six supporting columns, and a buoyancy chamber. The buoyancy chamber mainly consists of a cabin, a hatch, a piston, two nozzles and several sealing rings. The piston separates liquid and gas, so the buoyancy can be adjusted by a fluid power system, which changes the proportion of liquid and gas in the chamber. Each two adjacent sections are connected by a universal joint fixed on wiring disks by nuts, so that each joint has a rotation range of $\pm 30^{\circ}$ in two degrees of freedom (DOFs) of movement.

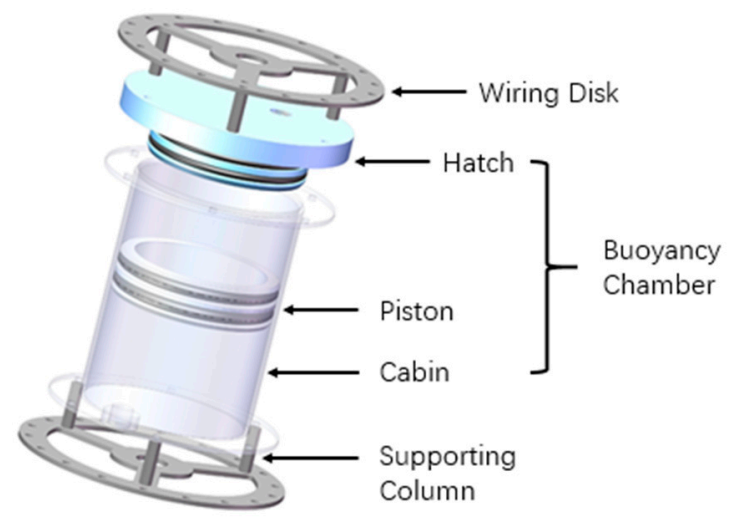

Figure 2. Structure of a section.

\subsection{Working Principle of Buoyancy Regulation System (BRS)}

The BRS of each section is composed of micro pump, flow meter, solenoid valve and connecting pipelines. Its working principle is shown in Figure 3. The liquid medium in the buoyancy chamber is water, and the gas medium is air. The buoyancy of each section is adjusted by changing the volume of water in the chamber by the pump control system. The driving unit of the BRS is installed on the base, connected to the execution unit through pipelines. This avoids the waterproof problem of the electrical system and simplifies the structure's design. 


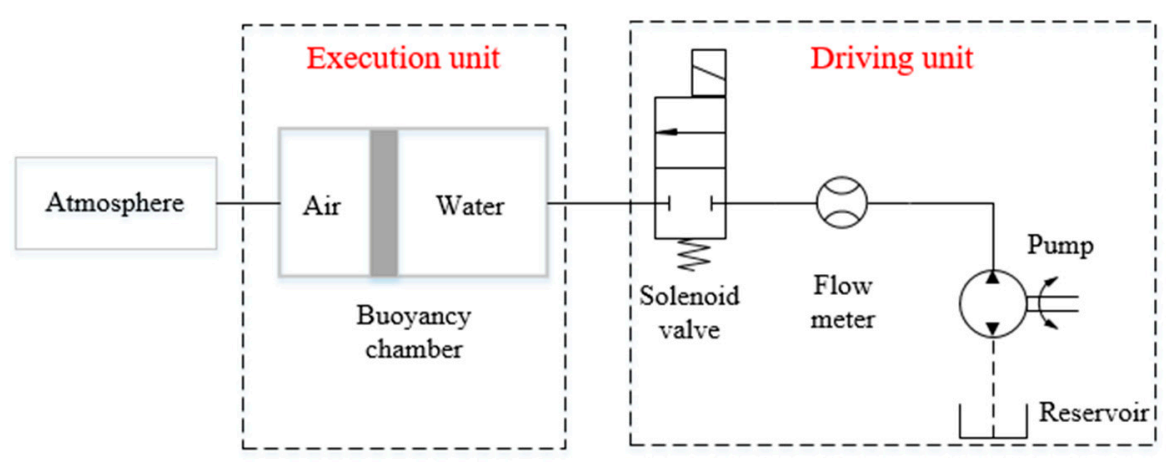

Figure 3. Working principle of buoyancy regulation system (BRS).

\section{Modeling}

\subsection{Kinematics}

We create a geometric model of a joint, as shown in Figure 4. We create frame $\{\mathrm{O}\}$, frame $\left\{\mathrm{O}_{2 \mathrm{k}-2}\right\}$, and frame $\left\{\mathrm{O}_{2 \mathrm{k}-1}\right\}$ at the center of rotation of the universal joint, the center of wiring disk $2 \mathrm{k}-2$, and the center of wiring disk $2 k-1$, respectively ( $k$ is the section number from the base, $k=1,2$, $3, \ldots, n)$. $\mathrm{R}$ represents the distance from the wiring hole to the center of the wiring disk, and $\alpha$ represents the angle of $\mathbf{R}$ relative to the $\mathrm{Y}$ axis of the disk, which is called the cable deflection angle (bold indicates vector, the same below). The two rotation angles of frame $\left\{\mathrm{O}_{2 \mathrm{k}-1}\right\}$ relative to frame $\left\{\mathrm{O}_{2 \mathrm{k}-2}\right\}$ are $\theta_{\mathrm{i}}$ (refer to the $\mathrm{Z}$ axis) and $\varphi_{\mathrm{i}}$ (refer to the $\mathrm{Y}$ axis). In addition, let $\mathrm{OO}_{2 \mathrm{k}-2}=\mathrm{OO}_{2 \mathrm{k}-1}=\mathrm{D}$, $\mathrm{O}_{2 \mathrm{k}-1} \mathrm{O}_{2 \mathrm{k}}=\mathrm{H}$.

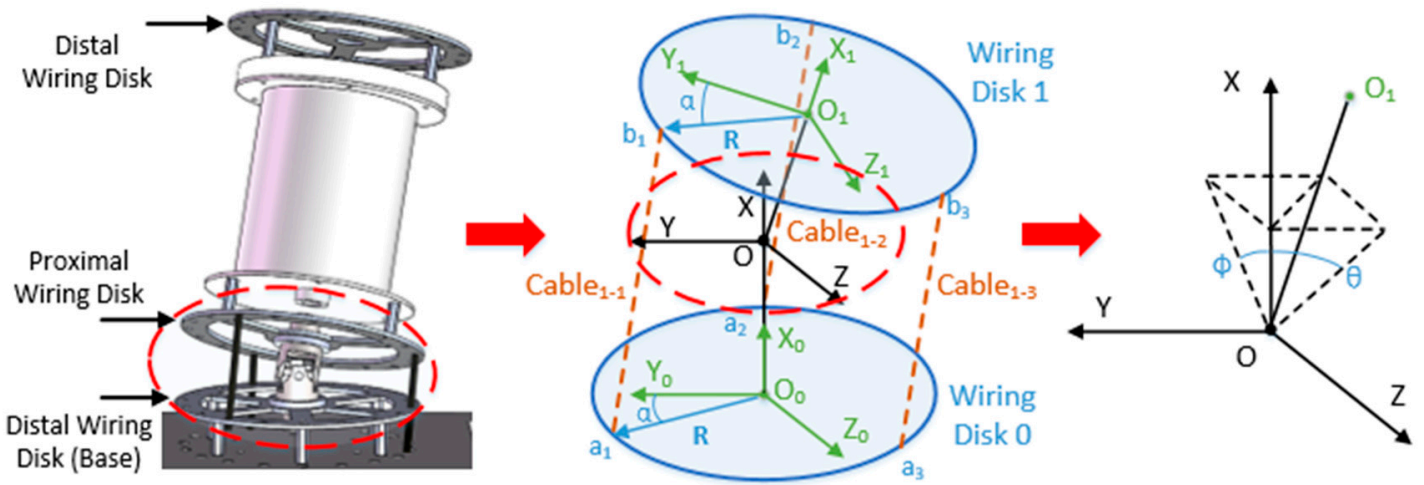

Figure 4. Joint model of the manipulator.

Assuming that the UCDM has $\mathrm{n}$ sections in total, $\alpha_{\mathrm{i}, \mathrm{j}}$ represents the cable deflection angle of the $\mathrm{j}$-th cable that controls the $\mathrm{i}$-th joint $(\mathrm{i}=1,2,3, \ldots, \mathrm{n} ; \mathrm{j}=1,2,3)$. Each section is controlled by 3 cables, and their cable deflection angles differ by $2 \pi / 3$. Assuming that each disk has $s$ wiring holes evenly distributed in the circumferential direction, let $\alpha_{1,1}=0$, then we have:

$$
\alpha_{i, j}=(i-1) \times \frac{2 \pi}{s}+(j-1) \times \frac{2 \pi}{3} .
$$

From (1), the coordinate of $\mathrm{a}_{1}$ in frame $\left\{\mathrm{O}_{2 \mathrm{k}-2}\right\}$ and the coordinate of $\mathrm{b}_{1}$ in frame $\left\{\mathrm{O}_{2 \mathrm{k}-1}\right\}$ are both $\left(0, R \cos \alpha_{i, j}, R \sin \alpha_{i, j}\right)$. Then we only require the coordinate of $b_{1}$ in frame $\left\{O_{2 k-2}\right\}$ to derive the distance between $a_{1}$ and $b_{1}$. This distance represents the length of the $\mathrm{j}$-th cable controlling the $\mathrm{i}$-th joint between the $\mathrm{k}-\mathrm{th}$ and $(\mathrm{k}-1)$-th section, denoted as $\mathrm{l}_{\mathrm{i}, \mathrm{j}, \mathrm{k}}(\mathrm{i} \geq \mathrm{k})$. Frame $\left\{\mathrm{O}_{2 \mathrm{k}-1}\right\}$ can be derived from frame $\left\{\mathrm{O}_{2 \mathrm{k}-2}\right\}$ through the transformation matrix Tr:

$$
\operatorname{Tr}=\operatorname{Trans}(\mathrm{D}, 0,0) \operatorname{Rot} Z\left(\theta_{\mathrm{i}}\right) \operatorname{Rot} Y\left(\varphi_{\mathrm{i}}\right) \operatorname{Trans}(\mathrm{D}, 0,0),
$$


where Trans () represents the translation function, $\operatorname{Rot} Z()$ and $\operatorname{Rot} Y()$ represent the rotation function refer to Z-axis and Y-axis. Let the coordinate of $b_{1}$ in frame $\left\{\mathrm{O}_{2 k-1}\right\}$ and frame $\left\{\mathrm{O}_{2 k-2}\right\}$ be $\mathrm{p}_{\mathrm{i}, \mathrm{j}, \mathrm{k}}$ and $\operatorname{Tr} \times \mathrm{p}_{\mathrm{i}, \mathrm{j}, \mathrm{k}}$, respectively, we have:

$$
l_{i, j, k}=\left\|a_{1} b_{1}\right\|=\left\|\operatorname{Tr} \times p_{i, j, k}-p_{i, j, k}\right\| .
$$

Then, the length of the $\mathrm{j}$-th cable controlling the $\mathrm{i}$-th joint can be derived as follows:

$$
\mathrm{L}_{\mathrm{i}, \mathrm{j}}=-\mathrm{H}+\sum_{\mathrm{k}=1}^{\mathrm{i}}\left(\mathrm{l}_{\mathrm{i}, \mathrm{j}, \mathrm{k}}+\mathrm{H}\right) .
$$

Furthermore, the transformation matrix from the base frame $\left\{\mathrm{O}_{0}\right\}$ to the frame at the end of the $\mathrm{k}$-th section (that is, frame $\left\{\mathrm{O}_{2 \mathrm{k}}\right\}$ ) can be derived as follows:

$$
{ }_{0}^{\mathrm{k}} \operatorname{Tr}=\prod_{1=1}^{\mathrm{k}}\left({ }_{21-2}^{21-1} \operatorname{Tr} \times \operatorname{Trans}(\mathrm{D}, 0,0)\right) .
$$

where ${ }_{21-2}^{21-1} \operatorname{Tr}$ represents the transformation matrix from frame $\left\{\mathrm{O}_{21-2}\right\}$ to frame $\left\{\mathrm{O}_{21-1}\right\}$.

For any wiring hole $\mathrm{p}_{\mathrm{i}, \mathrm{j}, \mathrm{k}}$ on wiring disk $2 \mathrm{k}$, its coordinate at the same position in the base frame $\left\{\mathrm{O}_{0}\right\}$ is $\mathrm{p}_{\mathrm{i}, \mathrm{j}, 0}$. From (5), the coordinates of $\mathrm{p}_{\mathrm{i}, \mathrm{j}, \mathrm{k}}$ in the base frame $\left\{\mathrm{O}_{0}\right\}$ can be derived as follows:

$$
\mathrm{p}_{\mathrm{i}, \mathrm{j}, \mathrm{k}}={ }_{0}^{\mathrm{k}} \operatorname{Tr} \times \mathrm{p}_{\mathrm{i}, \mathrm{j}, 0} \text {. }
$$

\subsection{Dynamics}

The basic goal of the dynamic analysis in this article is to solve all the cable tensions under the condition of known pose and motion state of the manipulator. The mechanical analysis is based on the following assumptions:

1. The links and the joints are assumed as rigid body;

2. The deformation and the mass of the cables are neglected;

3. The tension is equal at every point on the same cable. The cable only transmits tension but not pressure, that is: we always have $T_{k, j} \geq 0$.

Assuming that the wiring disk $2 \mathrm{k}-2$ is a fixed wiring disk (as shown in Figure 5, taking the base disk as an example, $\mathrm{k}=1$ ), its coordinate system is the ground coordinate system. Define UCDM's end close to the base as the proximal end, and the end away from the base as the distal end. Then in Figure 5, the wiring disk $2 \mathrm{k}-1$ is the proximal wiring disk of section $\mathrm{k}$, and the wiring disk $2 \mathrm{k}$ is the distal wiring disk of section $\mathrm{k}$. After analysis, the forces on section $\mathrm{k}$ include the following:

1. The inertial force $-\mathrm{m}_{\mathrm{k}} * \mathbf{a}_{\mathrm{k}-1}$ and moment of inertia $-\mathrm{J}_{\mathrm{k}} * \mathbf{A}_{\mathrm{k}-1}$ generated by the movement of the first ( $k-1)$-th sections from the base (it should be noted that $\mathbf{a}, \mathbf{A}, \mathbf{v}, \mathbf{w}, \mathbf{g}$, etc. mentioned in this section are all vectors in frame $\left\{\mathrm{O}_{2 \mathrm{k}-1}\right\}$. If there is a vector in the ground coordinate system, it needs to be transformed to frame $\left\{\mathrm{O}_{2 \mathrm{k}-1}\right\}$ using the transformation matrix);

2. Gravity $\mathrm{G}_{\mathrm{k}}$;

3. Buoyancy $\mathbf{B}_{\mathrm{k}}$;

4. The supporting force $\mathbf{F}_{\mathrm{k}-1}$ and torque $\mathbf{M}_{\mathrm{k}-1}$ from the former section;

5. The reaction torque $-\mathbf{M}_{\mathrm{k}}$ and reaction force $-\mathbf{F}_{\mathrm{k}}$ of the supporting force from the latter section;

6. Pressures generated by the cables (due to bending) passing through the proximal wiring disk and the distal wiring disk, which are $\mathbf{N}_{\mathrm{i}, \mathrm{j}}, \mathrm{k}$, pro and $\mathbf{N}_{\mathrm{i}, \mathrm{j}, \mathrm{k} \text {, dis; }}$

7. The friction force generated by the cable passing through proximal and distal wiring disks, which are $\mathbf{f}_{i, j, k}$, pro and $\mathbf{f}_{i, j, k}$, dis; 
8. The resultant force $\mathbf{T}_{\mathrm{k}, \mathrm{j}}$ (approximately equal to the pulling force, explained later) of the pulling force, frictional force and other forces caused by the cable connected to the proximal wiring disk;

9. The water resistance $\mathbf{F d}_{\mathrm{k}}$.

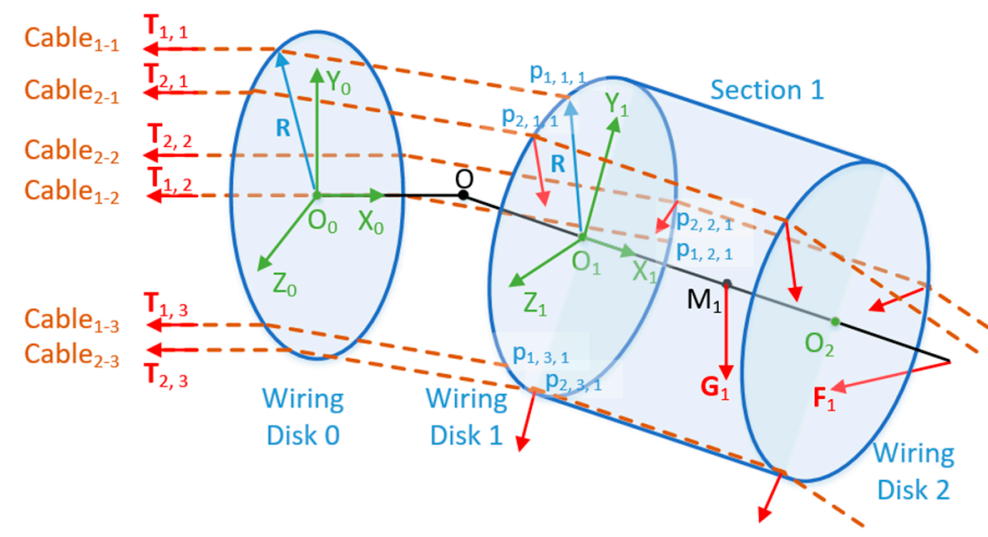

Figure 5. Mechanical analysis of a section.

To get each force and torque, let the moment of inertia of the section around $\mathrm{O}$ be $\mathrm{J}_{\mathrm{k}}$, and the angular acceleration be $\mathbf{A}_{\mathrm{k}}$. Then we have:

$$
\mathrm{J}_{\mathrm{k}} * \mathbf{A}_{\mathrm{k}}=\sum \boldsymbol{\tau}_{\mathrm{k}}
$$

where:

$$
\mathrm{J}_{\mathrm{k}}=\mathrm{J}_{0}+\mathrm{J}_{\mathrm{water}}
$$

where $\mathrm{J}_{0}$ is the moment of inertia of the mechanical structure, and $\mathrm{J}_{\mathrm{water}}$ is the moment of inertia of the water in the buoyancy chamber of this section.

$\sum \tau_{\mathrm{k}}$ is the sum of the moments on point $\mathrm{O}$, which are produced by forces and torques listed in 1-9 above, including:

1. Moment of inertia:

$$
\tau_{\mathrm{I}, \mathrm{k}}=-\mathrm{J}_{\mathrm{k}} * \mathbf{A}_{\mathrm{k}-1}
$$

2. Moment of gravity:

$$
\tau_{\mathrm{G}, \mathrm{k}}=\mathrm{G}_{\mathrm{k}} \times \mathbf{O M}_{\mathrm{k}}
$$

where:

$$
\begin{gathered}
\mathrm{G}_{\mathrm{k}}=\mathrm{g} * \mathrm{~m}_{\mathrm{k}}, \\
\mathrm{m}_{\mathrm{k}}=\mathrm{m}_{0}+\mathrm{m}_{\text {water }}
\end{gathered}
$$

where $m_{0}$ is the mass of the mechanical structure, and $m_{\text {water }}$ is the mass of the water in the buoyancy chamber of this section. $\mathbf{O M}_{k}$ is the force arm of gravity, and the coordinates of $\mathbf{M}_{k}$ can be obtained by calculating the position of the centroid;

3. Moment of buoyancy:

$$
\boldsymbol{\tau}_{\mathrm{B}, \mathrm{k}}=\mathbf{B}_{\mathrm{k}} \times\left(\mathbf{D}+\frac{\mathbf{H}}{2}\right),
$$

and since the structure of each section is the same, its buoyancy is a constant (the direction will change when converted to frame $\left.\left\{\mathrm{O}_{2 \mathrm{k}-1}\right\}\right)$. The buoyancy acts on the midpoint of $\mathrm{O}_{1} \mathrm{O}_{2}$, so its force arm is $\mathbf{D}+\frac{\mathbf{H}}{2}$;

4. The torque $\mathbf{M}_{\mathrm{k}-1}$ from the former section ( $\mathbf{F}_{\mathrm{k}-1}$ does not produce a torque to $\left.\mathrm{O}\right)$; 
5. The reaction torque $-\mathbf{M}_{\mathrm{k}}$ and the torque of reaction force $-\mathbf{F}_{\mathrm{k}}$ :

$$
\boldsymbol{\tau}_{\mathrm{F}, \mathrm{k}}=-\mathbf{F}_{\mathrm{k}} \times(2 * \mathbf{D}+\mathbf{H}) \text {, }
$$

where the force arm is $2 * \mathbf{D}+\mathbf{H}$;

6. Since the mass of each point on the cable is negligible, the resultant force of friction and pressure on the point is equal to the resultant force of the cable tension on both sides of the point. We call this resultant force the deformation force. For cable $\mathrm{L}_{\mathrm{i}, \mathrm{j}}$, the deformation forces on the proximal wiring disk of the $\mathrm{k}$-th section are:

$$
\mathbf{N N}_{\mathrm{i}, \mathrm{j}, \mathrm{k}, \text { pro }}=\mathrm{T}_{\mathrm{i}, \mathrm{j}} *\left(\mathbf{H}-\mathbf{l}_{\mathrm{i}, \mathrm{j}, \mathrm{k}}\right),
$$

their force arms are $\mathbf{D}+\mathbf{R}_{\mathrm{i}, \mathrm{j}}$, and their torques are:

$$
\boldsymbol{\tau}_{\mathrm{NN}, \mathrm{k}, \mathrm{pro}}=\sum_{\mathrm{i}=\mathrm{k}+1}^{\mathrm{n}} \sum_{\mathrm{j}=1}^{3} \mathbf{N N}_{\mathrm{i}, \mathrm{j}, \mathrm{k}, \mathrm{pro}} \times\left(\mathbf{D}+\mathbf{R}_{\mathrm{i}, \mathrm{j}}\right) .
$$

The deformation forces on the distal wiring disk are:

$$
\mathbf{N N}_{\mathrm{i}, \mathrm{j}, \mathrm{k}, \mathrm{dis}}=\mathrm{T}_{\mathrm{i}, \mathrm{j}} *\left(\mathbf{1}_{\mathrm{i}, \mathrm{j}, \mathrm{k}}-\mathbf{H}\right),
$$

their force arms are $\mathbf{H}+\mathbf{D}+\mathbf{R}_{\mathrm{i}, \mathrm{j}}$, and their torques are:

$$
\boldsymbol{\tau}_{\mathrm{NN}, \mathrm{k}, \mathrm{dis}}=\sum_{\mathrm{i}=\mathrm{k}+1}^{\mathrm{n}} \sum_{\mathrm{j}=1}^{3} \mathbf{N N}_{\mathrm{i}, \mathrm{j}, \mathrm{k}, \mathrm{dis}} \times\left(\mathbf{H}+\mathbf{D}+\mathbf{R}_{\mathrm{i}, \mathrm{j}}\right) ;
$$

7. Similar to 6., the resultant force of one cable controlling this section can be approximated as the cable tension at this point. Then the torques of cable tensions are:

$$
\boldsymbol{\tau}_{\mathrm{T}, \mathrm{k}}=\sum_{\mathrm{j}=1}^{3} \mathbf{T}_{\mathrm{k}, \mathrm{j}} \times\left(\mathbf{D}+\mathbf{R}_{\mathrm{i}, \mathrm{j}}\right),
$$

where the cable tension $\mathbf{T}_{k, j}$ 's direction is $-\mathbf{l}_{i, j, k}$, and its magnitude $T_{k, j}$ is the unknown quantity to be obtained. The force arms of the tensions are $\mathbf{D}+\mathbf{R}_{\mathrm{i}, \mathrm{j}}$;

8. Moment of water resistance:

$$
\boldsymbol{\tau}_{\mathrm{Fd}, \mathrm{k}}=\mathbf{F d}_{\mathrm{k}} \times\left(\mathbf{D}+\frac{\mathbf{H}}{2}\right) .
$$

The magnitude of water resistance Fd can be calculated by (21) [38].

$$
\mathrm{Fd}=\mathrm{Cd}(\operatorname{Re}) * \mathrm{v}^{2} * \mathrm{~S} * \rho,
$$

where,

Cd: the drag coefficient;

Re: the Reynolds number that reflect the flow characteristics;

$\mathrm{v}$ : the relative velocity of spherical underwater robot to the fluid;

$\mathrm{S}$ : the cross-sectional area;

$\rho$ : the density of the fluid.

The direction of water resistance is opposite the direction of section movement. It acts approximately on the midpoint of $\mathrm{O}_{1} \mathrm{O}_{2}$, so its force arm is $\mathbf{D}+\frac{\mathbf{H}}{2}$. 
This is a redundancy problem using three cables to determine a plane. But under the constraints of assumption 3., Equation (7) can obtain a unique solution. Substitute the obtained $\mathbf{T}_{\mathrm{k}, \mathrm{j}}$ into the dynamic model established above. Let the translational acceleration of this section be $\mathbf{a}_{\mathrm{k}}$, we have:

$$
\mathrm{M}_{\mathrm{k}} * \mathrm{a}_{\mathrm{k}}=\sum \text { force }_{\mathrm{k}}
$$

then the last unknown force $\mathbf{F}_{\mathrm{k}-1}$ is obtained.

So far, the dynamic state of the section has been uniquely determined.

\section{Solution and Discussion}

\subsection{Solution}

In this section, we numerically solve the dynamic model of the UCDM prototype, as shown in Figure 6. We discretize the motion into multiple transients, and each transient solves the current parameters based on the parameters preset and obtained from the previous transient (the preset parameters mainly include angular acceleration and piston moving speed, and the solved parameters in each transient mainly include angular velocity, pose, and tension). For each transient, the program calculates section by section from the distal end to the proximal end. In the calculation process, $\mathbf{F}_{\mathrm{k}-1}$ and $\mathbf{M}_{\mathrm{k}-1}$ of each section are used as $-\mathbf{F}_{\mathrm{k}}$ and $-\mathbf{M}_{\mathrm{k}}$ of the former section. Hence, we can simulate the motion of UCDM and obtain the time histories of all cable tensions during the motion.

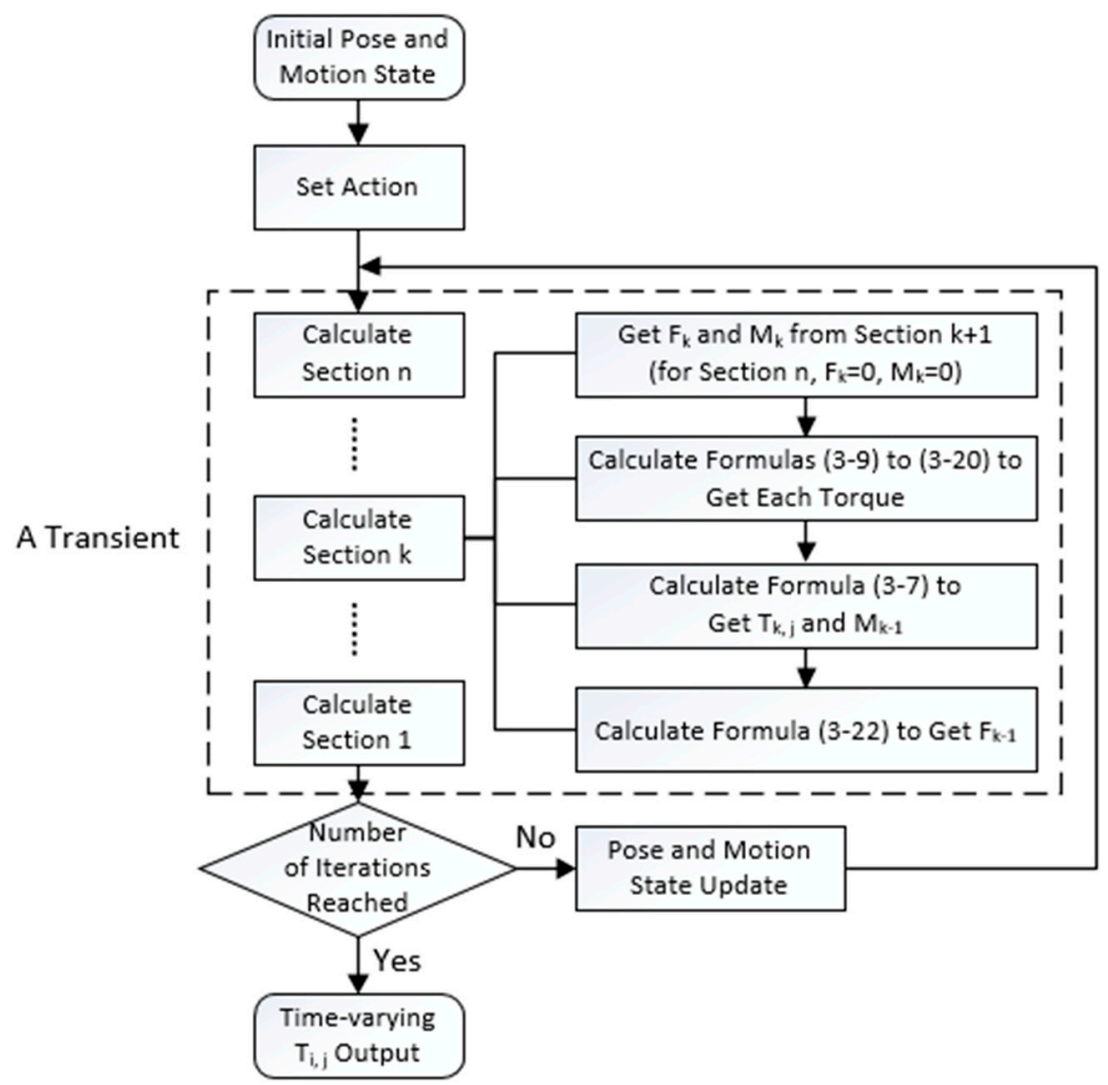

Figure 6. Steps for numerical solution of the dynamic model.

Since the buoyancy only acts in the vertical direction, we solve the movement of the manipulator in the vertical plane numerically. The angles of the starting posture and the end posture are assumed 
as follows. The movement represents the action of the manipulator to lift an object from a low position, as shown in Figure 7.

Starting posture : $\theta_{\mathbf{i}}=-0.45 ; \varphi_{\mathrm{i}}=0$; end posture : $\theta_{\mathbf{i}}=0 ; \varphi_{\mathrm{i}}=0$.

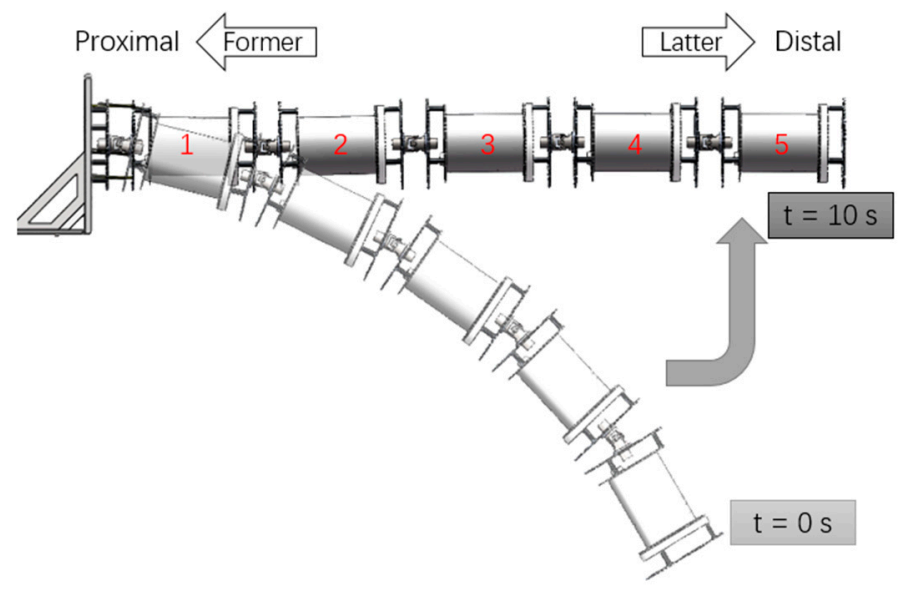

Figure 7. Movement of the manipulator.

We also assume the movement starts and ends with 0 velocity and a certain acceleration (in order to start or stop the manipulator's movement). While the manipulator is moving, each section pumps out the water in the buoyancy chamber at a constant speed $\mathrm{v}_{\text {pump }}=0.8 \mathrm{~cm} / \mathrm{s}$, providing buoyancy to help the manipulator lift the object. For comparison, perform the same movement on the same manipulator (but without BRS). The Reynolds number $\operatorname{Re} \approx 7100$, so the drag coefficient $\mathrm{Cd} \approx 1$. The acting time of the movement is 10s and the step length of the solution is $\Delta t=0.5 \mathrm{~s}$ (small enough to show the characteristics of tension). Solution results of the tension on each cable are shown in Figures 8-12.

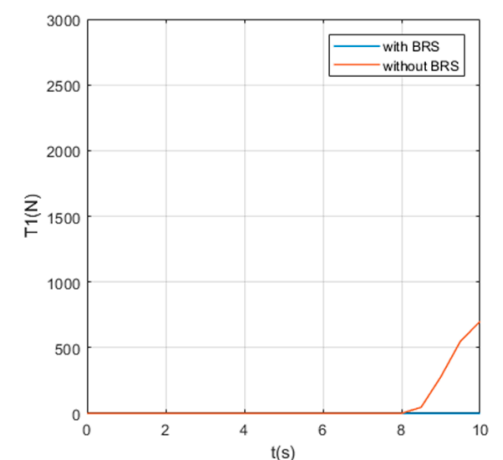

(a) $\mathrm{T}_{1,1}$

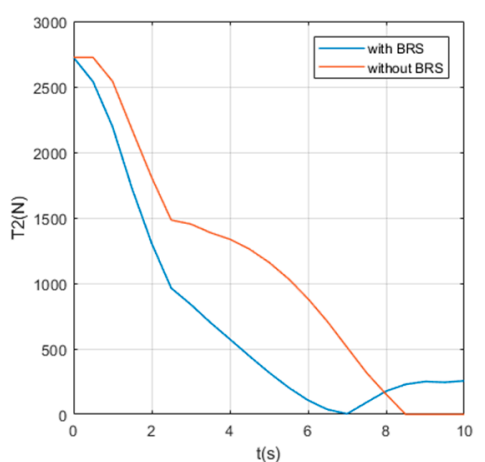

(b) $\mathrm{T}_{1,2}$

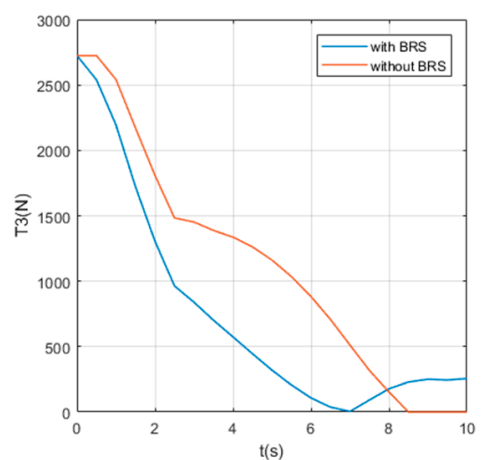

(c) $\mathrm{T}_{1,3}$

Figure 8. The time histories of the tensions on cables controlling Section 1. 


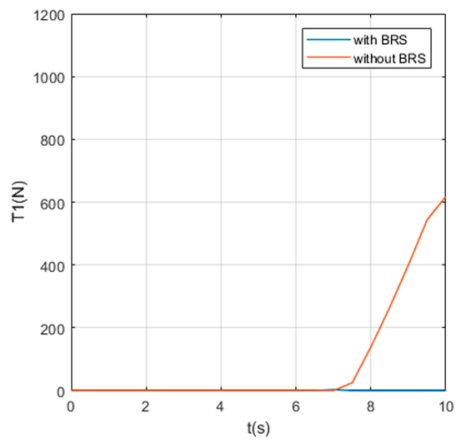

(a) $\mathrm{T}_{2,1}$

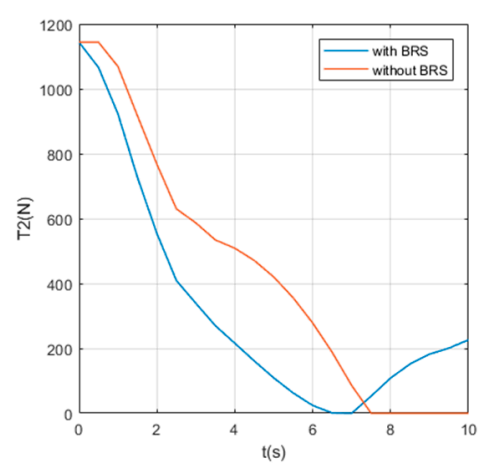

(b) $\mathrm{T}_{2,2}$

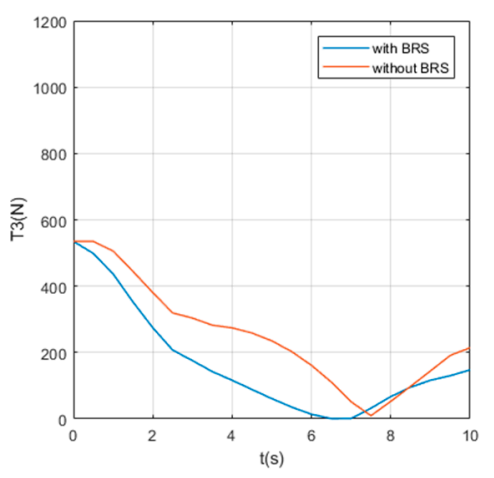

(c) $\mathrm{T}_{2,3}$

Figure 9. The time histories of the tensions on cables controlling Section 2.

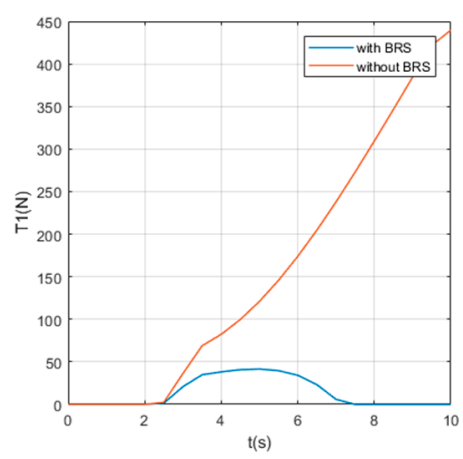

(a) $\mathrm{T}_{3,1}$

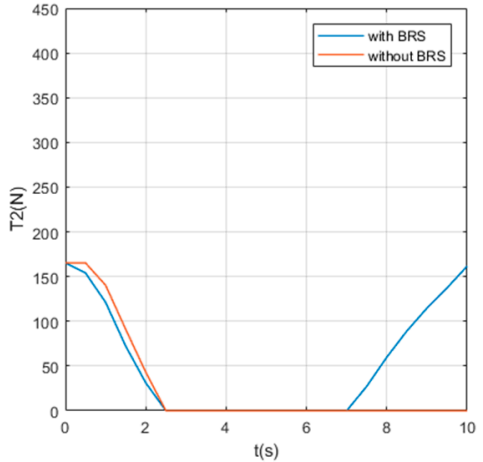

(b) $\mathrm{T}_{3,2}$

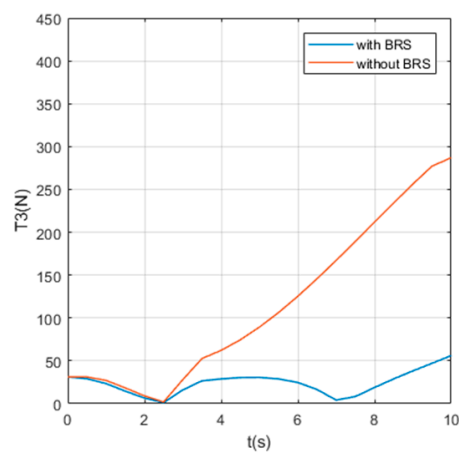

(c) $\mathrm{T}_{3,3}$

Figure 10. The time histories of the tensions on cables controlling Section 3.

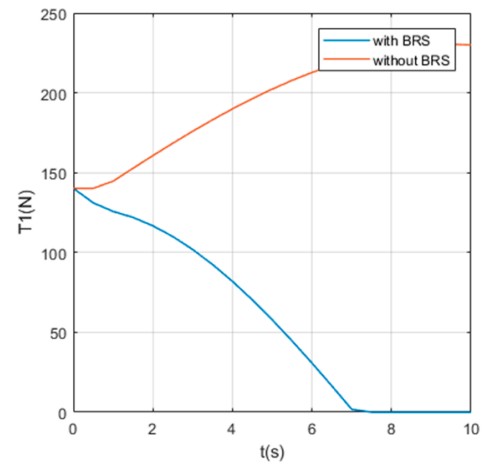

(a) $\mathrm{T}_{4,1}$

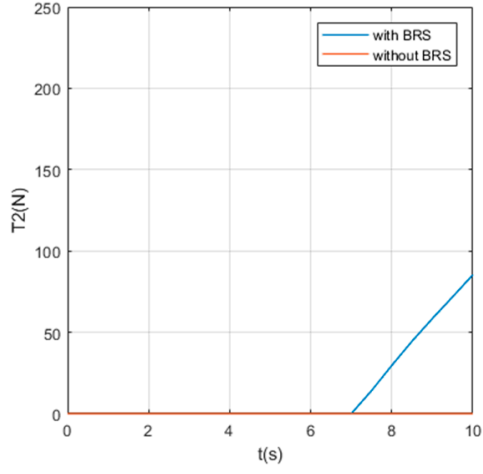

(b) $\mathrm{T}_{4,2}$

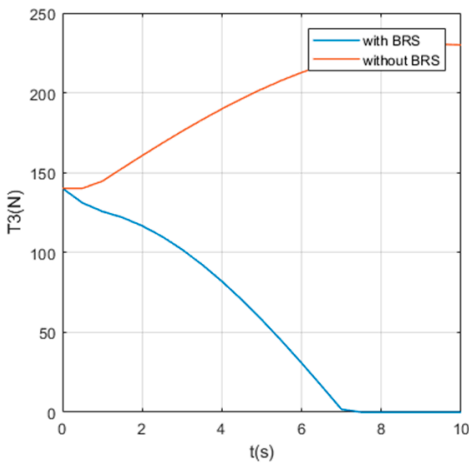

(c) $\mathrm{T}_{4,3}$

Figure 11. The time histories of the tensions on cables controlling Section 4 . 


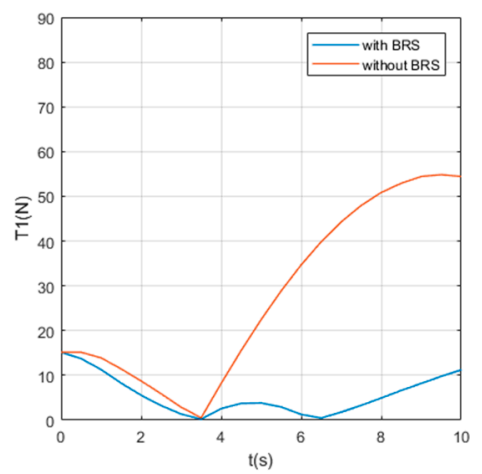

(a) $\mathrm{T}_{5,1}$

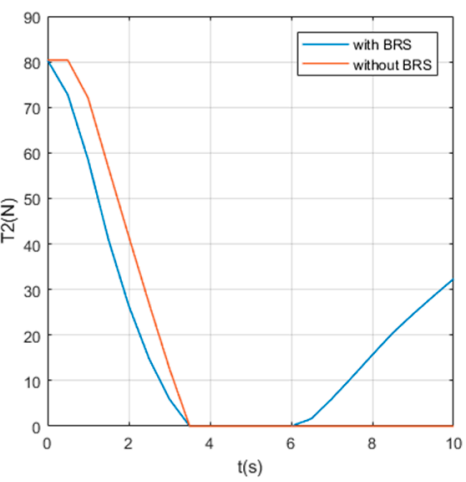

(b) $\mathrm{T}_{5,2}$

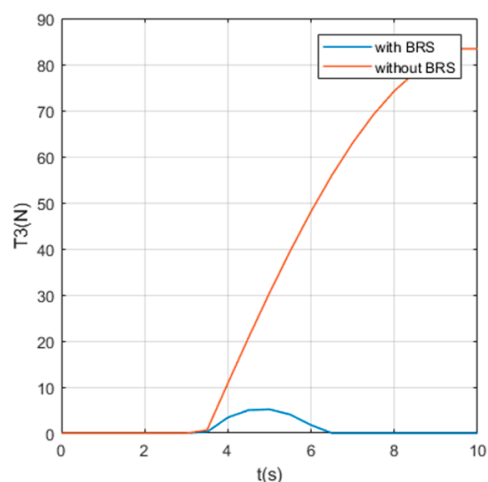

(c) $\mathrm{T}_{5,3}$

Figure 12. The time histories of the tensions on cables controlling Section 5.

\subsection{Discussion}

Due to the large number of cables and the obvious difference in tensions' time histories, it is difficult for us to obtain an intuitive feature that is generally valid for all curves from Figures 8-12. Nevertheless, by comparing the two cases with and without BRS, we can see that the tensions on most cables are reduced by BRS. On several cables, the effect of BRS on reducing tension is very significant (for example, the average tension on cable $3-1$ is reduced by $91.62 \%$ ). We believe that is because the buoyancy balances the weight of the UCDM, which in general makes the motion require smaller driving forces. On a few cables, BRS increases the tension slightly (for example, the average tension on cable $5-2$ increased by $18.62 \%$ ). This is because these cables are located in the lower half of each section. When the buoyancy of a section is greater than the gravity of this sections, the cables in the lower half are pulled by the upward net buoyancy, hence the tensions are increased.

For underwater manipulators, the power required to perform actions is worthy of attention, because the power and energy that underwater robots can provide are relatively limited. During the motion of the UCDM, the sum of the power on all cables in a transient can be calculated by (23):

$$
P=\sum_{i=1}^{n} \sum_{j=1}^{3} T_{i, j} * \frac{\Delta L_{i, j}}{\Delta t} .
$$

This formula sums the effects of BRS on all cables and presents them on two curves, as shown in Figure 13. It is obvious that BRS significantly reduces the power consumption on cables. The average power is reduced by $51.04 \%$, and the maximum power is reduced by $13.92 \%$.

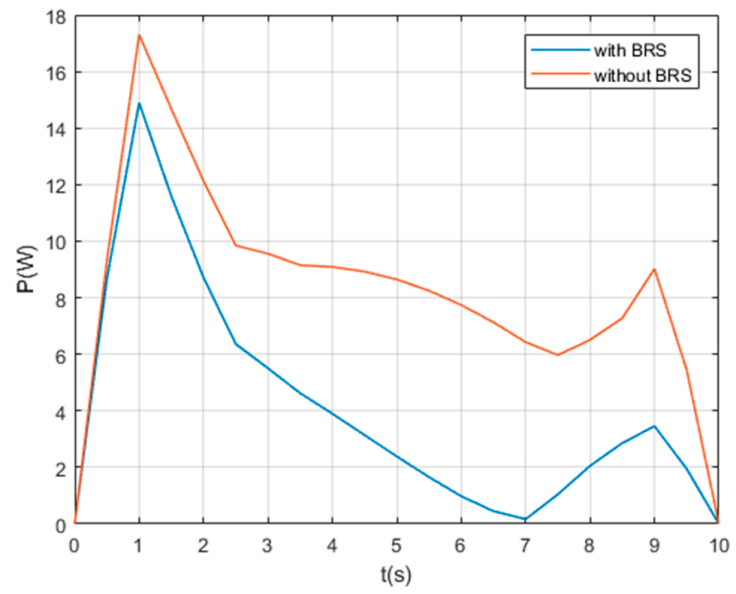

Figure 13. The time histories of the power of all cables. 
At $t=1 \mathrm{~s}$, both cases are at the maximum power. This is within our expectations, because at this moment the manipulator has just begun to move. It has a large acceleration, so the driving forces have to overcome a large inertial force and water resistance. Similarly, at $t=9 \mathrm{~s}$, each cable pulls the manipulator to stop the movement, so the power curve also has a local maximum here. Of particular concern is that at $t=7 \mathrm{~s}$, the power with BRS drops to a minimum. We believe that these are because the net buoyancy of each section is close to 0 at this time, so each cable tension is near its minimum value (as shown in Figure 8). This result shows that if the buoyancy can be adjusted to dynamically match the load so that the net buoyancy of the manipulator is controlled close to 0 , the driving force of each cable can be minimized. Using buoyant materials or air-filled chambers cannot accomplish this goal because their buoyancy is not adjustable. This result can be used to significantly reduce the tension of each cable, which is expected to greatly reduce the power of driving forces.

\section{Conclusions}

This article proposes an underwater cable-driven manipulator with a fluid-power buoyancy regulation system for underwater operations, and conducts dynamic analysis. Considering the buoyancy effect on the UCDM's motion among all hydrodynamic factors, we analyzed the coupling relationship between cable tension, inter-joint force, buoyancy, and water resistance, established dynamic equations using Newton-Euler method, and numerically solved the time histories of the tension on each cable in a vertical movement. The results show that under the effect of BRS, the sum of the driving forces required to perform the movement is reduced by about $50 \%$. Furthermore, by dynamically matching the load with buoyancy, the sum of the driving forces is expected to be reduced by up to $90 \%$. This result indicates that BRS can reduce the energy demand of the UCDM, because the effect of buoyancy effectively balances the negative impact of the manipulator's self-weight.

With BRS, it is expected to greatly increase the number of sections of the UCDM, which will enlarge its arm span and buoyancy regulation range. This improvement is feasible, but too many pump sets will make the system complex and hard to control. In general, we proposed an UCDM with high DOFs and low energy demand. This can be used in performing complex underwater actions and underwater tasks with limited energy supply. In future, the control strategy of distributed buoyancy regulation will be studied to optimize the power of the driving motors.

Author Contributions: Conceptualization, W.S. and S.Z.; methodology, T.W.; software, Z.Y.; validation, T.W., Z.Y., W.S. and S.Z.; formal analysis, W.S.; investigation, T.W.; resources, W.S. and S.Z.; data curation, Z.Y.; writing - original draft preparation, T.W.; writing-review and editing, W.S.; visualization, W.S. and S.Z.; supervision, W.S. and S.Z.; project administration, W.S. and S.Z.; funding acquisition, W.S. and S.Z. All authors have read and agreed to the published version of the manuscript.

Funding: This research was funded by the National Natural Science Foundation of China, grant number 51705452, and supported by the Fundamental Research Funds for the Central Universities.

Conflicts of Interest: The authors declare no conflict of interest.

\section{References}

1. Lee, Y.; Lee, Y.; Chae, J.; Choi, H.-T.; Yeu, T. A Study on the Development of Underwater Robot Control System for Autonomous Grasping. J. Korea Robot. Soc. 2020, 15, 39-47. [CrossRef]

2. Bemfica, J.; Melchiorri, C.; Moriello, L.; Palli, G.; Scarcia, U. A three-fingered cable-driven gripper for underwater applications. In Proceedings of the 2014 IEEE international conference on robotics and automation (ICRA), Hong Kong, China, 31 May-7 June 2014; pp. 2469-2474.

3. Manjunatha, M.; Selvakumar, A.A.; Godeswar, V.P.; Manimaran, R. A low cost underwater robot with grippers for visual inspection of external pipeline surface. Procedia Comput. Sci. 2018, 133, 108-115. [CrossRef]

4. Kumar, S.; Rastogi, V.; Gupta, P. Recent Developments in Modeling and Control of Underwater Robot Manipulator: A Review. Indian J. Sci. Technol. 2016, 9, 48. [CrossRef] 
5. Chutia, S.; Kakoty, N.M.; Deka, D. A review of underwater robotics, navigation, sensing techniques and applications. In Proceedings of the Advances in Robotics, IIT Delhi, New Delhi, 28 June-2 July 2017; pp. 1-6.

6. Huang, H.; Tang, Q.; Li, J.; Zhang, W.; Bao, X.; Zhu, H.; Wang, G. A review on underwater autonomous environmental perception and target grasp, the challenge of robotic organism capture. Ocean Eng. 2020, 195, 106644. [CrossRef]

7. Wu, Y.; Ta, X.; Xiao, R.; Wei, Y.; An, D.; Li, D. Survey of underwater robot positioning navigation. Appl. Ocean Res. 2019, 90, 101845. [CrossRef]

8. Mazumdar, A.; Lozano, M.; Fittery, A.; Asada, H.H. A compact, maneuverable, underwater robot for direct inspection of nuclear power piping systems. In Proceedings of the 2012 IEEE International Conference on Robotics and Automation, Saint Paul, MN, USA, 14-18 May 2012; pp. 2818-2823.

9. Shen, Z.; Zhong, H.; Xu, E.; Zhang, R.; Yip, K.C.; Chan, L.L.; Chan, L.L.; Pan, J.; Wang, W.; Wang, Z. An Underwater Robotic Manipulator with Soft Bladders and Compact Depth-Independent Actuation. Soft Robot. 2020, 7, 535-549. [CrossRef] [PubMed]

10. Li, B.; Wang, Y.; Zhu, K.; Chen, B.; Wu, H. Structure design and control research of a novel underwater cable-driven manipulator for autonomous underwater vehicles. Proc. Inst. Mech. Eng. Part M J. Eng. Marit. Environ. 2020, 234, 170-180. [CrossRef]

11. Robotics, O. Snake-arm robots access the inaccessible. Nucl. Technol. Int. 2008, 1, 92-94.

12. Endo, G.; Horigome, A.; Takata, A. Super dragon: A 10-m-long-coupled tendon-driven articulated manipulator. IEEE Robot. Autom. Lett. 2019, 4, 934-941. [CrossRef]

13. Burgner-Kahrs, J.; Rucker, D.C.; Choset, H. Continuum robots for medical applications: A survey. IEEE Trans. Robot. 2015, 31, 1261-1280. [CrossRef]

14. Yoon, H.-S.; Yi, B.-J. A 4-DOF flexible continuum robot using a spring backbone. In Proceedings of the 2009 International Conference on Mechatronics and Automation, Jilin, China, 9-12 August 2009; pp. 1249-1254.

15. Nahar, D.; Yanik, P.M.; Walker, I.D. Robot tendrils: Long, thin continuum robots for inspection in space operations. In Proceedings of the 2017 IEEE Aerospace Conference, Big Sky, MT, USA, 4-11 March 2017; pp. 1-8.

16. Dong, X.; Axinte, D.; Palmer, D.; Cobos, S.; Raffles, M.; Rabani, A.; Kell, J. Development of a slender continuum robotic system for on-wing inspection/repair of gas turbine engines. Robot. Comput.-Integr. Manuf. 2017, 44, 218-229. [CrossRef]

17. Wang, Y.; Yan, F.; Zhu, K.; Chen, B.; Wu, H. A new practical robust control of cable-driven manipulators using time-delay estimation. Int. J. Robust Nonlinear Control 2019, 29, 3405-3425. [CrossRef]

18. Kang, R.; Branson, D.T.; Guglielmino, E.; Caldwell, D.G. Dynamic modeling and control of an octopus inspired multiple continuum arm robot. Comput. Math. Appl. 2012, 64, 1004-1016. [CrossRef]

19. Jiang, L.; Gao, B.; Zhao, J. Kinematic and static analysis of a cable-driven parallel robot with a flexible link spine. In Proceedings of the 2015 IEEE International Conference on Robotics and Biomimetics (ROBIO), Zhuhai, China, 6-9 December 2015; pp. 31-36.

20. Tonapi, M.M.; Godage, I.S.; Walker, I.D. Next generation rope-like robot for in-space inspection. In Proceedings of the 2014 IEEE Aerospace Conference, Big Sky, MT, USA, 1-8 March 2014; pp. 1-13.

21. Kim, B.S.; Kim, M.K.; Cho, Y.; Hamed, E.E.; Gillette, M.U.; Cha, H.; Miljkovic, N.; Aakalu, V.K.; Kang, K.; Son, K.-N. Electrothermal soft manipulator enabling safe transport and handling of thin cell/tissue sheets and bioelectronic devices. Sci. Adv. 2020, 6, eabc5630. [CrossRef]

22. Tamadon, I.; Soldani, G.; Dario, P.; Menciassi, A. Novel robotic approach for minimally invasive aortic heart valve surgery. In Proceedings of the 2018 40th Annual International Conference of the IEEE Engineering in Medicine and Biology Society (EMBC), Honolulu, Hawaii, 17-21 July 2018; pp. 3656-3659.

23. Ranzani, T.; Gerboni, G.; Cianchetti, M.; Menciassi, A. A bioinspired soft manipulator for minimally invasive surgery. Bioinspiration Biomim. 2015, 10, 035008. [CrossRef]

24. Ip, B.C.; Cui, F.; Tripathi, A.; Morgan, J.R. The bio-gripper: A fluid-driven micro-manipulator of living tissue constructs for additive bio-manufacturing. Biofabrication 2016, 8, 025015. [CrossRef]

25. Yamaguchi, T.; Ambe, Y.; Ando, H.; Konyo, M.; Tadakuma, K.; Maruyama, S.; Tadokoro, S. A mechanical approach to suppress the oscillation of a long continuum robot flying with water jets. IEEE Robot. Autom. Lett. 2019, 4, 4346-4353. [CrossRef] 
26. Endo, G.; Hagiwara, T.; Nakamura, Y.; Nabae, H.; Suzumori, K. A proposal of super long reach articulated manipulator with gravity compensation using thrusters. In Proceedings of the 2018 IEEE/ASME International Conference on Advanced Intelligent Mechatronics (AIM), Auckland, New Zealand, 9-12 July 2018; pp. 1414-1419.

27. Takeichi, M.; Suzumori, K.; Endo, G.; Nabae, H. Development of a 20-m-long Giacometti arm with balloon body based on kinematic model with air resistance. In Proceedings of the 2017 IEEE/RSJ International Conference on Intelligent Robots and Systems (IROS), Vancouver, BC, Canada, 24-28 September 2017; pp. 2710-2716.

28. Shang, W.; Zhang, B.; Zhang, B.; Zhang, F.; Cong, S. Synchronization control in the cable space for cable-driven parallel robots. IEEE Trans. Ind. Electron. 2018, 66, 4544-4554. [CrossRef]

29. Wang, Y.; Yan, F.; Chen, J.; Ju, F.; Chen, B. A new adaptive time-delay control scheme for cable-driven manipulators. IEEE Trans. Ind. Inform. 2018, 15, 3469-3481. [CrossRef]

30. Wang, Y.; Jiang, S.; Chen, B.; Wu, H. A new continuous fractional-order nonsingular terminal sliding mode control for cable-driven manipulators. Adv. Eng. Softw. 2018, 119, 21-29. [CrossRef]

31. Giorelli, M.; Renda, F.; Calisti, M.; Arienti, A.; Ferri, G.; Laschi, C. A two dimensional inverse kinetics model of a cable driven manipulator inspired by the octopus arm. In Proceedings of the 2012 IEEE International Conference on Robotics and Automation, Saint Paul, MN, USA, 14-18 May 2012; pp. 3819-3824.

32. Webster III, R.J.; Jones, B.A. Design and kinematic modeling of constant curvature continuum robots: A review. Int. J. Robot. Res. 2010, 29, 1661-1683. [CrossRef]

33. Xu, W.; Liu, T.; Li, Y. Kinematics, dynamics, and control of a cable-driven hyper-redundant manipulator. IEEE/ASME Trans. Mechatron. 2018, 23, 1693-1704. [CrossRef]

34. Renda, F.; Giorelli, M.; Calisti, M.; Cianchetti, M.; Laschi, C. Dynamic model of a multibending soft robot arm driven by cables. IEEE Trans. Robot. 2014, 30, 1109-1122. [CrossRef]

35. Xu, G.; Shen, X.; Yu, K. Modeling and Hydrodynamic Performance for a deep ocean manipulator based on Numerical Approach. JCP 2013, 8, 1192-1199. [CrossRef]

36. Lau, D.; Oetomo, D.; Halgamuge, S.K. Generalized modeling of multilink cable-driven manipulators with arbitrary routing using the cable-routing matrix. IEEE Trans. Robot. 2013, 29, 1102-1113. [CrossRef]

37. Hassan, M.; Khajepour, A. Analysis of bounded cable tensions in cable-actuated parallel manipulators. IEEE Trans. Robot. 2011, 27, 891-900. [CrossRef]

38. Kundu, P.K.; Cohen, I.M.; Dowling, D. Fluid Mechanics, 4th ed.; Academic Press: Boston, MA, USA, 2008; pp. 421-472, ISBN 9780123737359.

Publisher's Note: MDPI stays neutral with regard to jurisdictional claims in published maps and institutional affiliations.

(C) 2020 by the authors. Licensee MDPI, Basel, Switzerland. This article is an open access article distributed under the terms and conditions of the Creative Commons Attribution (CC BY) license (http://creativecommons.org/licenses/by/4.0/). 